\title{
LEITURA E DOCÊNCIA: A PERSPECTIVA DO PNAIC NA FORMAÇÃO DO PROFESSOR-LEITOR
}

\author{
READING AND TEACHING: PNAIC PERSPECTIVE IN TEACHER- \\ READER FORMATION
}

\author{
Ilsa do Carmo Vieira Goulart ${ }^{1}$ \\ Giovanna Rodrigues Cabral ${ }^{2}$
}

\begin{abstract}
Resumo: Este estudo tem por centralidade a compreensão de como se organizam as propostas de formação docente dos profissionais que atuam na alfabetização, na vertente das ações leitoras. Assim, objetiva-se refletir sobre o processo de formação do professor-leitor nas discussões teóricas dispostas nos cadernos de formação do Programa Pacto Nacional pela Alfabetização na Idade Certa (PNAIC). Para tanto, realizou-se uma pesquisa qualitativa, por meio da análise documental dos cadernos de formação do PNAIC, com caráter descritivo das marcas teóricas e metodológicas direcionadas à formação do professor-leitor ou de atividades leitoras que exigem ações e posicionamentos pedagógicos. O referencial teórico baseou-se na concepção enunciativa-discursiva da linguagem em Bakhtin, na concepção de leitura como prática social em Chartier, nos estudos de Bronckart sobre as noções de atividade e ação. $\mathrm{O}$ estudo aponta para o processo de formação do professor-leitor demarcado por ações leitoras que se articulam num plano motivacional, intencional e interpretativo.
\end{abstract}

Palavras-chave: Formação continuada; professor-leitor; prática pedagógica.

\begin{abstract}
This study focuses on understanding how the proposals for teacher training of professionals working in literacy are organized, in terms of reading actions. Thus, the objective is to reflect on the teacher-reader formation process in the theoretical discussions arranged in the formation books of the National Pact for Literacy in the Right Age Program (PNAIC). To this end, a qualitative research was carried out, through the documentary analysis of the PNAIC training books, with a descriptive character of the theoretical and methodological marks aimed at the formation of the teacher-reader or reader activities that require pedagogical actions and positions. The theoretical framework was based on the enunciative-discursive conception of language in Bakhtin, on the conception of reading as a social practice in Chartier, in Bronckart's studies on the notions of activity and action. The study points to the teacher-reader formation process demarcated by reader actions that are articulated in a motivational, intentional and interpretive plan.
\end{abstract}

Keywords: Continuing education. Teacher-reader. Pedagogical practice.

\section{Considerações iniciais}

A Constituição Federal/88 define a Educação como um direito prioritário contemplando essa questão em vários tópicos e tornando o acesso ao ensino obrigatório e gratuito um direito público subjetivo (artigo 208, VII, $\S 1^{\circ}$ ). A Lei de Diretrizes e Bases da Educação Nacional - LDB/96 fortaleceu a tendência à descentralização normativa, executiva e financeira do sistema educacional e repartiu competências entre as instâncias do poder (federal, estadual e municipal), enfatizando a responsabilidade de estados e municípios pela universalização do Ensino Fundamental.

\footnotetext{
${ }^{1}$ Universidade Federal de Lavras, Lavras, MG, Brasil.

${ }^{2}$ Universidade Federal de Lavras, Lavras, MG, Brasil.
} 
Assim, a legislação vigente garante o acesso à escola pública de crianças e jovens de $4 \mathrm{a}$ 17 anos, destacando a educação como direito de todos e apontando o dever do Estado e da família no cumprimento desse direito. No entanto, quando verificamos os resultados do Censo Demográfico (2010) e das avaliações externas, como a Avaliação Nacional da AlfabetizaçãoANA (2016) sobre os índices de aprendizagem das crianças em leitura e escrita, percebe-se que esse acesso à educação, à escola pública não vem acompanhado da aprendizagem das habilidades básicas para aquisição do sistema de escrita alfabético.

Muitas discussões sobre a falta de êxito que o país enfrenta na alfabetização de crianças e jovens terminam, quase sempre, na recomendação de formar profissionais bem preparados com vistas a uma transformação sobre a prática pedagógica.

Assim, a formação do professor tornou-se uma tônica, mobiliando iniciativas governamentais na implementação de políticas públicas a fim de potencializar práticas exitosas na alfabetização. Uma das últimas iniciativas implementada em todo o país com o objetivo de promover a formação continuada de alfabetizadores em âmbito nacional foi o Pacto Nacional pela Alfabetização na Idade Certa (PNAIC).

O PNAIC foi instituído pelo Governo Federal, em 2012, por intermédio do Ministério da Educação como uma das ações do Plano de Desenvolvimento da Educação, com a finalidade de garantir a alfabetização plena de crianças até oito anos de idade em todo o território brasileiro, atendendo assim, ao elencado no inciso II, do art. $2^{\circ}$ do Decreto 6094/2007, que destacou as diretrizes do Compromisso Todos pela Educação. Essa diretriz está alinhada com a meta cinco do PNE (2014 - 2024): "alfabetizar todas as crianças, no máximo, até o final do terceiro ano do Ensino Fundamental”.

Analisando as propostas de formação continuada de professores ofertadas pelo Governo Federal, percebe-se o PNAIC como uma política de continuidade do governo brasileiro voltada à formação dos educadores alfabetizadores, que começou com o Programa de Formação de Professores Alfabetizadores - PROFA, em 2001, com a proposta de orientar as ações educativas de alfabetização na Educação Infantil, no Ensino Fundamental e na Educação de Jovens e Adultos, seguido pelo Pró Letramento, iniciado em 2005.

Implementado a partir de 2013 em todas as unidades da federação, o PNAIC assume como um dos pontos significativos a oferta de formação de professores alfabetizadores, ampliando as discussões sobre a alfabetização, na perspectiva do letramento, nas redes de ensino, nas escolas e nas instituições de ensino superior. Regido por junção interligada de programas, de materiais e de referências curriculares e de ações pedagógicas, sob a ótica da formação continuada dos professores alfabetizadores. (OMETTO; GOULART, 2017).

As produções acadêmicas a respeito do PNAIC avolumam-se nos últimos anos, com as pesquisas de Fonseca (2013), Freire (2016), Resende (2015), Alferes (2017), que discutem o programa de formação e apresentam diferentes vertentes no que confere uma reflexão crítica da proposta de formação continuada. Por ser um programa de abrangência nacional, diferentes olhares e propostas de estudos colocam em discussão o programa de formação, ora sob a ótica da proposta idealizadora do PNAIC, ora sob a articulação com a prática pedagógica, ora sob o olhar do professor alfabetizador, mas o que pouco se observa nas produções é uma reflexão mais aprofundada dos materiais de cunho teórico e metodológico que compõem o eixo da formação, com direcionamento reflexivo ao processo de formação de um professor-leitor.

Se por um lado tem-se a discussão encorpada a respeito da formação dos professores para atuarem no processo de alfabetização, contribuindo diretamente com a aprendizagem da leitura e da escrita dos leitores; por outro, se mostram escassas as pesquisas que discutem a formação leitora do docente. Por estar relacionado com conhecimento, a atuação do professor requer 
domínio de conteúdos e de estratégias de didático-metodológicas, o que demanda contato constante com textos de orientação da prática pedagógica.

Nessa perspectiva, os estudos de Batista (1998, p. 5) apontam que para assumir a posição de leitor, para esses agentes, requer um conjunto de "[...] competências e esquemas de percepção e apreciação, que são transmitidos pela escola e, posteriormente, a serem, por eles, transmitidos na escola". Segundo Batista (1998), os professores seriam, antes de tudo, leitores "escolares" e tenderiam a investir, mesmo em suas leituras não diretamente voltadas para escola e a prática docente, as competências e as disposições escolares, adquiridas escolarmente. Assim, a formação leitora parece percorrer uma instância de leituras inicias de um contexto escolar, para, posteriormente revivê-las, nas escolas na condição de docência. Frente a isso, pode-se pensar que os encontros de formação continuada se mostram espaços que podem diversificar e/ou intensificar as leituras teórico-metodológicas, com vistas às ações procedimentais.

Desse modo, ao considerar a leitura como uma prática social de produção de sentidos, de que forma as orientações e discussões teórico-metodológicas estão dispostas nos cadernos de formação do PNAIC, de modo a garantir a formação do professor como leitor, em primeira instância, antes de assumir o papel de mediador da leitura? Até que ponto é possível identificar elementos que problematizam os usos sociais das atividades leitoras e como é abordada a temática do processo de formação leitora dos professores da educação básica?

Em busca de respostas sobre a relação entre a leitura e a docência, assume-se por objetivo refletir o processo de formação do professor-leitor nas discussões teóricas dispostas nos cadernos de formação do Programa Pacto Nacional pela Alfabetização na Idade Certa (PNAIC), disponibilizados em 2012. Para isso, realizou-se uma pesquisa de abordagem qualitativa, tomando como procedimento metodológico uma análise documental dos cadernos de formação do PNAIC, com caráter descritivo e exploratório das marcas teóricas e metodológicas direcionadas à formação do professor-leitor ou de atividades leitoras que exigem ações pedagógicas.

\section{Reflexões sobre a leitura e a formação do professor-leitor na perspectiva dialógica e discursiva}

O olhar reflexivo para o processo de formação do professor-leitor coloca o estudo em espaços de demarcação de posições teóricas. Depara-se com uma representação social da ausência de práticas leitores de professores da educação básica (BATISTA, 1996; 1997; 1998), contudo, estudos apontam para o foco argumentativo de um professor-leitor, que realiza diferentes atividades de leitura, visto que no exercício do magistério "[...] lê e faz ler os seus alunos. O professor lê e provê conteúdos. O professor lê e prevê caminhos. O professor lê e se vê melhor nas suas caminhadas. O professor lê e se reconstrói nas experiências. O professor lê e se revitaliza incessantemente". (SILVA, 2009, p. 28).

Tais ações de leitura ocorrem, segundo Silva (2009), movidas numa articulação entre o fazer docente com tudo o que cerca, em que as esferas do âmbito pessoal, profissional e organizacional são fomentadas pelas práticas de leitura.

Neste sentido, abarcando a leitura numa dimensão mais ampla como prática social de produção de sentidos, tem-se uma relação direta com a linguagem como processo enunciativodiscursivo, por ser um "produto da interação social", conforme descreve Bakhtin/ Volochínov (2012, p. 126), compreende-se a leitura também como um processo dialógico. Haja vista que todo ato de leitura compõe de uma ação dialógica. (ROJO, 2004).

Para Rojo (2004), o diálogo que se estabelece entre leitor e texto parte de um percurso demarcado por ações e atuações, como definir qual o objetivo ou as metas da atividade de 
leitura, o que acarretará a ativação de estratégias para se alcançar tal finalidade. Perceber as relações de intertextualidade e de discursividade, de modo a colocar o texto em relação com outros textos já lidos e conhecidos. Perceber as relações entre linguagens (imagens, som, imagens, sinais, gráficos, entre outros) como elementos constitutivos dos sentidos dos textos em consonância com escrita. Elaborar uma apreciação estética, afetiva ou ética, quando, no momento da leitura, pode-se replicar reagir, manifestar sentimentos, ideias, apontar uma dada apreciação, opinião ou valoração. (ROJO, 2004).

No jogo dialógico da leitura, segundo Goulart (2016) a palavra torna-se um lugar comum entre interlocutores, que se manifesta por discursos e, por sua vez, concretiza-se em textos, sejam eles verbais ou não verbais, permite um movimento de interação que ocorre por meio da atividade leitora, oferecendo significados múltiplos pelo leitor. Nesta relação tríade entre leitor, texto e leitura que ocorre a produção de sentidos.

Por ser o livro um "ato de fala impresso" (BAKHTIN/ VOLOCHÍNOV, 2012, p. 127), torna-se um objeto provocativo de manifestações de discussões, argumentações, (im)posições, verificações, indagações ou (dis)concordâncias, que, de modo ativo, desencadeia ações interiores de comentar ou criticar como elementos de um diálogo.

O ato da leitura como diálogo, segundo Cosson (2014, p. 41) está na relação de compreensão do texto, em que ao construir sentidos para o texto é possível compartilhar sentidos amplos de uma ideia ou de um determinado posicionamento ideológico. Segundo o autor, a leitura percorre um circuito envolvendo quatro elementos: o autor, o texto, o leitor e o contexto, que se articulam para uma produção de sentidos. Nesta proposição, Cosson (2014, p. 41), explicita que ao definir "[...] leitura como diálogo, compreendemos que o gesto inaugural da leitura começa com o leitor fazendo uma indagação".

$\mathrm{O}$ ato de ler requer uma ação do leitor diante do texto, um ato questionador, problematizador, reflexivo da própria prática, uma atitude leitora do fazer pedagógico, que "[...] envolve o movimento dinâmico, dialético entre o fazer e o pensar sobre o fazer" (FREIRE, 1996, p. 38).

Se o ato de ler, no processo de formação permite uma atitude dialógica sobre o fazer, temse, segundo Freire (1996), um pensar crítico da prática. O ato de reflexão parte de outras ações, entre elas desponta-se "[...] a curiosidade como inquietação indagadora", descrita por Freire (1996, p. 32), em que há a não saciedade do saber, há uma indiscrição para o ato de conhecer, há uma sede insaciável que move ou direciona o processo de aprendizagem.

Nesta perspectiva, a formação do professor-leitor parte da compreensão do ato de leitura, não apenas como uma atividade de apropriação de concepções, conceitos, ideias ou aprofundamento de aspectos teóricos, ou ainda, da absorção de aspectos metodológicos, mas como um ato dialógico. Quando, frente ao discurso, há um posicionamento verbal - ou atitudinal - tem-se uma ação, na qual pode-se conceber "ação" na perspectiva de Bronckart (2008, p. 121), ao propor uma distinção de "atividade" como o ato de leitura do agir envolvendo as dimensões motivacionais e intencionais num plano coletivo e a "ação" como uma leitura do agir que envolve, também, as dimensões da motivação e da intencionalidade, mas em um plano particular, pessoal.

Certos de que os textos - no caso do objeto de estudo: os cadernos de formação do PNAIC - trazem uma dada carga de intencionalidade, na qual postula significações e modos distintos de ler dispostos em sua materialidade, pela forma como organizam os conteúdos, as imagens, as formas de estruturação da linguagem, dos protocolos de leitura, dispositivos gráficos e textuais, tem-se uma ação do leitor sobre e com o texto. Deste modo, Chartier (2001, p. 78) explicita que a leitura pode ser compreendida como "[...] prática criadora, inventiva, produtora, e não anulá-la no texto lido, como se o sentido desejado por seu autor devesse inscrever-se com toda a imediatez e transparência nem desvio, no espírito de seus leitores". São os atos de leitura que dão aos textos seus significados. Atos de um leitor ativo, por serem os mesmos textos e 
livros, objetos de leitura que sofrem decifrações ou compreensões múltiplas e, por vezes, contraditórias, segundo Chartier (2001, p. 79).

Tendo em vista, que os professores seriam, antes de tudo, leitores "escolares", conforme Batista (1998) e que tenderiam a investir, mesmo em suas leituras não diretamente voltadas para escola e a prática docente, parte das competências e das disposições escolares, adquiridas ou utilizadas escolarmente. A formação leitora do professor demonstra marcas iniciais das ações escolares, de modo que parece se atenuar quando se está em exercício, inclinando-se ou restringindo-se em leituras direcionadas às propostas didáticas.

Ao considerar a leitura como atividade determinante no processo de formação continuada, por proporcionar uma ação dialógica e discursiva frente ao texto, desencadeando atos de reflexão crítica e posicionamentos sobre a prática pedagógica, entende-se que há um esforço de leitura e da condução das ações, visto que "[...] conjunto de textos selecionados pelos professores pode dar visibilidade ao planejamento de uma disciplina. Trata-se especialmente de artigo cientifico de revistas especializadas, capítulos de livros e de manuais de disciplina da educação". (ANDRADE 2007, p. 125)

Os estudos de Andrade (2006) demonstram que o proceder de um saber docente provém de uma ação de aproximar conhecimentos de fontes diversas, gerados em momentos, locais e mediados por circunstâncias diversas em seu processo de formação. Podem ser vistos como "instâncias formadoras", nas quais os sujeitos já se encontraram anteriormente como aprendizes, leitores, alunos. Para Andrade (2006, p. 7), são estes "“...] processos de socialização dos sujeitos professores, nestas instâncias, vão construindo a identidade profissional docente. O saber docente se constitui a partir dos múltiplos discursos enunciados nas instituições de formação, que continua sua constituição ao serem reapropriados, ressignificados e reorganizados pelo professor, em seu discurso docente".

\section{As orientações do PNAIC para a formação do professor-leitor}

A formação continuada de alfabetizadores pelo PNAIC caracterizou-se, em sua primeira versão, por ser um curso presencial, com cerca de dois anos de duração, perfazendo uma carga horária de 120 horas por ano. Desenvolveu-se a partir de metodologia de estudos individuais e coletivos, atividades práticas e socialização de experiências.

Segundo os estudos de Ometto e Goulart (2017), a organização dos conteúdos do programa de formação PNAIC, estruturou-se na primeira versão, em 2012, em 8 (oito) unidades, divididas 3 (três) coletâneas, denominadas por Anos (1, 2 e 3), já para a Educação do Campo, há 8 (oito) cadernos específicos, não separados por ano. O conjunto de Cadernos de Formação apresenta-se em 4 (quatro) volumes: Caderno de Apresentação, Caderno de Formação, Caderno de Educação Especial e Caderno de Avaliação no ciclo de alfabetização: reflexões e sugestões, totalizando 36 (trinta e seis) Cadernos de Formação ${ }^{3}$.

A organização sistemática de todos os cadernos de formação distribui os conteúdos, a serem estudados, em quatro seções: 1) Iniciando a conversa, por ser uma seção introdutória, que apresenta a obra e qual a discussão temática a ser trabalhada em cada caderno, descrevendo os objetivos. 2) Aprofundando o tema é uma seção constituída por textos com discussões teórica, numa busca de articulação da abordagem conceitual a partir de relatos de experiências ou depoimentos de professores. 3) Compartilhando, tem por desígnio primar pelos direitos de aprendizagem nas diferentes áreas de ensino, adicionado com a indicação de materiais distribuídos pelo MEC, que, em concordância com os relatos de práticas e com as sugestões de

\footnotetext{
${ }^{3}$ O programa de formação apresentou outras versões em 2013-2014, em 2015-2016, em 2017-2018 para fim de atender ao objetivo proposto, neste estudo a pesquisa se deterá aos cadernos produzidos no período de 2012.
} 
atividades, a fim de serem utilizados pelos professores, em ala de aula; apresentando, ainda, instrumentos de registro da avaliação; lista de materiais didáticos, entre outros. 4) Aprendendo mais, faz o encerramento das discussões temáticas, subdividindo-se em sugestões de leitura, espaço em que há a indicação de livros, acompanhados de resenhas, e sugestões de atividades ou estratégias formativas, que podem ser indicadas como complemento das discussões entre os professores durante os encontros de formação.

Ao centrarem a pesquisa na seção 3, Ometto e Goulart (2017, p. 165) destacam que os textos dispostos na seção Compartilhando laboram uma função motivadora de diálogos entre professores ao compartilharem práticas pedagógicas bem sucedidas. Como discurso predominante tem-se a descrição e narração de ações, que, segundo as autoras, parece deixar um texto mais fluído e mais acessível, com ênfase no gênero textual de relatos de experiência.

A utilização dos relatos de experiência como gênero determinante e o compartilhar de práticas pedagógicas aparece com destaque em outras seções dos cadernos do PNAIC, e mesmo nos demais textos como depoimentos ou sugestões de atividades, partem de enunciados que procuram compartilhar uma situação vivenciada em sala de aula.

Em complementariedade à pesquisa realizada por Ometto e Goulart (2017), apresenta-se, neste estudo, uma análise dos cadernos de formação disponibilizados em 2012, com foco na seção 4 Aprendendo mais. Justifica-se que a delimitação do corpus investigativo, deve-se ao fato de retratar, de modo direcionado, o contexto de formação do professor-leitor, por isso optou-se pela análise dos conteúdos dos materiais dos 8 (oito) cadernos de cada coletânea dos anos de estudo, totalizando 24 (vinte e quatro) exemplares.

Dentre o montante da coletânea observou-se, na seção Aprendendo mais, os modos de organização da linguagem para a articulação da proposta de formação. Os 24 (vinte e quatro) cadernos apresentam uma organização sistemática dos conteúdos em cada seção. A seção Aprendendo mais se divide em duas propostas: uma referente às sugestões de leitura e outra às sugestões de atividades para os encontros de formação em grupo. Na primeira, apresentam-se 4 (quatro) indicações de leitura seguidas de uma síntese do texto recomendado, em cada livro da coletânea. São 32 (trinta e dois) textos preconizados em cada coletânea, num total de 96 (noventa e seis) textos sugeridos para leitura. Os textos indicados constituem-se de livros (49\%), capítulos de livros (24\%), artigos científicos (16\%), artigos publicados em anais de eventos (5\%), boletim (1\%), relatórios, (1\%), coletânea de programas de formação (1\%), tese (1\%) e jornal (1\%).

A segunda parte da seção apresenta sugestões de atividade para o encontro de formação. Trata-se de um texto descritivo com a definição das atividades a serem realizadas, sistematizando o passo a passo das ações formativas. Compõe-se de um discurso orientador em que os estudos ou temas estão distribuídos em encontros de 4 (quatro) horas, denominados de momentos, acompanhados da descrição do como as atividades podem ser apresentadas e trabalhadas nos encontros de formação. Caracterizado por ser um texto injuntivo ou instrucional está pautado na explicação e no método para a concretização de uma ação, ou seja, indicam o procedimento para realizar algo. Utiliza como recurso linguístico os verbos no imperativo, com a finalidade de prescrever, orientar e organizar uma ação.

Observa-se que a coletânea de modo geral se configura pela proposta de formação de um professor-leitor, ao oferecer diferentes textos para leituras, debates, com relação e reflexão da prática pedagógica. Nas duas propostas da seção estão presentes uma condução da ação leitora no processo de formação, que segundo Bronckart (2008, p. 121), o agir articula-se num plano motivacional, quando a proposta de formação sugere textos para leitura acompanhados de uma síntese das obras. Pauta-se numa ordem externa do material, que utiliza como complementariedade da ação formativa a proposição de outras leituras que dialogam com a temática estudada. Num plano intencional quando na seção apresenta-se as sugestões de 
atividades para os encontros de formação, percebe-se a intenção que conduz a ação formativa planejada com um dado propósito. Num plano interpretativo, quando mesmo em meio as orientações disponibilizadas, tem-se a ação do professor-leitor formador de outros professoresleitores, que se mantem pela ação de expressividade e particularidade dos agentes de formação do programa, em que "[...] a estrutura é o resultado do acúmulo de experiências de agentividade que variam em quantidade e em qualidade (em função dos contextos de mediação formativa) e que escalonam em uma temporalidade sempre particular". (BRONCKART, 2008, p. 122).

\section{Considerações finais}

Ao delimitarmos como objeto de estudo os cadernos de formação do PNAIC, entende-se que o programa de formação se apoia de modo estrutural nos materiais disponibilizados para os encontros com os professores alfabetizadores. Baliza-se a análise, a partir do corpus investigativo, nos cadernos de formação disponibilizados em 2012, com base na proposição de Chartier (2001) de que os mesmos textos e livros, em sua materialidade, caracterizam como objetos desencadeadores de decifrações múltiplas.

Certos da multiplicidade de interpretação, as observações apontam para uma organização sistematizada dos conteúdos de formação. Agrupados em coleções, o material de formação proporciona uma linguagem interativa com os professores alfabetizadores, ao oferecer discussões teóricas a partir de textos em gêneros acadêmicos, opta por priorizar um diálogo a partir de textos que, em sua maioria, compõem-se de relatos de experiências.

Na seção Aprendendo mais destaca-se um diálogo mais direcionado ao processo de formação do professor-leitor a partir de um texto provocativo de ações. A leitura implica uma ação do leitor frente ao texto, implica uma determinada maneira de ler e de interagir com e sobre o material de leitura. Os textos descritivos e injuntivos articulam-se num plano motivacional, num plano intencional e num plano interpretativo, que segundo Bronckart (2008) exigem tanto um posicionamento na realização de tarefas, numa dimensão do agir coletivo na elaboração e execução das atividades, quanto um posicionamento do agir singular, marcado pelas particularidades das ações e modos de percepção do fazer formativo e do processo interpretativo, que atribui ao agente intenções, motivos e responsabilidade no agir, de modo específico, da realização da ação leitora.

A relação entre a leitura e docência se mostra a partir de textos correlacionadas com as práticas pedagógicas, ou melhor, de textos que tratam das vivências escolares, de um diálogo a partir de uma cultura escolar para vencer representações sociais de um professor como um não-leitor, incapaz de reconhecer textos e impressos cujos princípios de apropriação teórica não dominem, de modo a minimizar uma relação tensa e, possivelmente, demarcada pela ausência de autonomia e pela busca de validação de suas leituras, como leitores ativos e atuantes. (BATISTA, 1998).

A leitura como prática social, conforme nos assegura Chartier (2001), perpassa uma relação em que se busca estabelecer relações de pertença social, de produção cultural e de identificação dos materiais de leitura que determinam um grupo. No caso, do processo de alfabetização, a análise do material de formação aponta uma articulação de ações leitoras, a partir da indicação de leituras que caracterizam a área em discussão, oferecendo ao professorleitor textos que discutem as temáticas e sugestões de práticas pedagógicas.

Embora observa-se lacunas no processo de formação do professor-leitor, que não esgotam a temática proposta, tem-se, por meio das iniciativas teórico-metodológicas propostas pelo programa de formação PNAIC, uma tentativa de oferecer instrumentos que viabilizem o desencadear de ações leitoras, de como compreender que a leitura se trata de um constante agir, 
de se buscar um posicionamento, de demarcar ações e atividades, num ato de "convocar o homem a tomar sua palavra", conforme descreve Queirós (2012, p. 62).

\section{Referências}

ALFERES, M. A. Pacto Nacional pela Alfabetização na Idade Certa: uma análise contextual da produção da política e dos processos de recontextualização. $2017244 \mathrm{f}$. Tese (Doutorado em Educação). Universidade Estadual de Ponta Grossa, Ponta Grossa, 2017.

ANDRADE, L. T. de. Por uma abordagem discursiva da formação docente. TEIAS, Rio de Janeiro, ano 7, n. 13-14, p. 1-9, jan./dez. 2006. Disponível em: https://www.epublicacoes.uerj.br/index.php/revistateias/article/view/24614/17593. Acesso em: 25 fev. 2020.

ANDRADE, L. T. de. Professores leitores e sua formação: transformações discursivas de conhecimentos de saberes. Belo Horizonte: Ceale/ Autêntica, 2007.

BATISTA, A. A. G. O ensino de Português e sua investigação: quatro estudos exploratórios. 1996. Tese (Doutorado em Educação). Programa de Pós-Graduação da Faculdade de Educação da UFMG, Belo Horizonte: 1996.

BATISTA, A. A. G. Aula de Português: discurso e saberes escolares. São Paulo: Martins Fontes, 1997.

BATISTA, A. A. G. A leitura incerta: a relação de professores(as) de Português com a leitura. Educação em Revista, Belo Horizonte, n. 27, p. 1-26, jul./dez. 1997.

BAKHTIN, M. Marxismo e filosofia da linguagem. Tradução Michel Lahud e Yara Frateschi Vieira. 13. ed. São Paulo: Hucitec, 2012.

BRASIL. Secretaria de Educação Básica. Pacto nacional pela alfabetização na idade certa. Ano 1: unidade 1 a 8. Brasília: MEC, SEB, 2012a.

BRASIL. Secretaria de Educação Básica. Pacto nacional pela alfabetização na idade certa. Ano 2: unidade 1 a 8. Brasília: MEC, SEB, 2012b.

BRASIL. Secretaria de Educação Básica. Pacto nacional pela alfabetização na idade certa. Ano 3: unidade 1 a 8. Brasília: MEC, SEB, 2012c.

BRONCKART, J.-P. O agir nos discursos: das concepções teóricas às concepções dos trabalhadores. Trad. Anna Rachel Machado, Maria de Lourdes Meirelles Matencio. Campinas: Mercado das Letras, 2008.

CHARTIER, R. (Org.). Práticas da leitura. Tradução Cristiane Nascimento. São Paulo: Estação da Liberdade, 2001.

COSSON, R. Círculos de leitura e letramento literário. São Paulo: Contexto, 2014. 
FREIRE, P. Pedagogia da autonomia: saberes necessários à prática educativa. São Paulo: Paz e Terra, 1996.

FREIRE, E. S. Avaliação formativa da alfabetização: uma proposta para acompanhar o desenvolvimento da leitura das crianças do $2^{\circ}$ ano do ensino fundamental. 2016. $189 \mathrm{f}$. Tese (Doutorado em Educação). Universidade Federal do Ceará, Centro de Humanidades, Fortaleza, 2016.

FONSECA, A. S. A. da. Avaliação do programa de alfabetização na idade certa - PNAIC: reflexos no planejamento e prática escolar. 2013. 125 f. Tese (Doutorado em Educação). Universidade Federal do Ceará, Centro de Humanidades, Fortaleza, 2013.

GOULART, I. do C. V. A compreensão e conceituação de livro num jogo de representações. Leitura: Teoria \& Prática, Campinas, São Paulo, v. 34, n. 67, p. 69-82, 2016. Disponível em: https://ltp.emnuvens.com.br/ltp/issue/view/16/showToc. Acesso em: 28 fev. 2020.

LAROSSA, J. Pedagogia Profana: danças, piruetas e máscaras. Trad. Alfredo Veiga-Neto. 5. ed. Belo Horizonte: Autêntica, 2010.

OMETTO, C. B. do N.; GOULART, I. do C. V. A alfabetização como prática discursiva: um olhar para as orientações de formação nos cadernos do PNAIC. In: MAGALHÃES, T.; GARCIA-REIS, A. R; FERREIRA, H. M. (Org.). Concepção discursiva de linguagem: ensino e formação docente. Campinas: Pontes, 2017. 151-172p.

QUEIRÓS, B. C. de; ABREU, J. (Org.). Sobre ler, escrever e outros diálogos. Belo Horizonte: Autêntica, 2012.

RESENDE, V. A. D. L. de. Análises dos pressupostos de linguagem nos cadernos de formação em língua portuguesa do Pacto Nacional pela Alfabetização na Idade Certa - PNAIC. 2015. 215 f. Tese (Doutorado em Educação). Universidade Estadual Paulista Júlio de Mesquita Filho, Faculdade de Filosofia e Ciências, 2015. Disponível em: http://hdl.handle.net/11449/123673. Acesso em 29 dez. 2019.

ROJO, R. Letramento e capacidade de leitura para a cidadania. São Paulo: Rede do Saber/CENP-SEE-SP, 2004. Disponível em: http://arquivos.info.ufrn.br/arquivos/2013121153a8f1155045828c12733b68e/Letramento e_capacidade_de_leitura_pra_cidadania_2004.pdf. Acesso em: 28 fev. 2020.

SILVA, E. T. da. O professor leitor. In: ROSING, T.; SANTOS, F. dos; MARQUES NETO, J. C. Mediação de leitura: Discussões e alternativas para a formação de leitores. São Paulo: Global, 2009. p. 23-36.

SOARES, M. O livro didático como fonte para a história da leitura e da formação do professorleitor. In: MARINHO, Marides (Org.). Ler e navegar: espaços e percursos da leitura. Campinas: Mercado das Letras, 2001. p. 31-76. 


\section{Sobre as autoras}

Ilsa do Carmo Vieira Goulart é doutora em Educação pela Faculdade de Educação da Universidade Estadual de Campinas (2013). Mestre em Educação pela Faculdade de Educação da Universidade Estadual de Campinas (2009). Graduada em Letras, pela Fundação de Ensino Superior do Vale do Sapucaí (1997). Professora do Departamento de Educação e do Programa de Pós-Graduação em Educação da Universidade Federal de Lavras.

E-mail: ilsa.goulart@ded.ufla.br.

Giovanna Rodrigues Cabral é graduada em Direito (2000) e Pedagogia (2001). Especialista em Direito Educacional (2005) e Gestão da Educação pública municipal (2016). Mestre em Educação pela Universidade Católica de Petrópolis (2010) e Doutora em Educação pela Pontifícia Universidade Católica do Rio de Janeiro (2015). Professora do Departamento de Educação da Universidade Federal de Lavras.

E-mail: giovanna.cabral@ufla.br. 